\title{
Analysis on the Strategic Position of 'Northern Sea Route' Based on '21st---Century Maritime Silk Route'
}

\author{
Xing Wei \\ Hainan Tropical Ocean University Department of Russian Hainan Sanya 572022 \\ weixing118@163.com
}

Keywords: "Maritime Silk Route"; Marine Cooperation between China and Russia; "Northern Sea Route"; Strategic Position

\begin{abstract}
Century Maritime Silk Route" is a new strategy China put forward to take the initiative to create harmonious diplomacy and meanwhile create favorable opportunity and external environment for its deepening reform while facing complicated global situation. China is a growing maritime power, which has to not only safeguard maritime territory but also adopt scientific technology to explore and develop maritime resources as well as maintain oceangoing sea route. In recent years, China has carried out deepening cooperation with Russia in terms of traditional areas such as energy, yet the cooperation in terms of Northern Sea Route remains scant. Therefore, China should take "21st-Century Maritime Silk Route" as an opportunity to mutually develop and utilize resources in arctic areas and "Northern Sea route", implement an early layout so as to conduct a new positioning and planning on the development of Northern Sea Route from a higher level and new perspective, and meanwhile take it as a crucial part while carrying out economic cooperation with Russia.
\end{abstract}

\section{Introduction}

There is no doubt that China is the world's second-largest economy with its economic development leading the way, which is deemed as an engine for world economic recovery and development. However, in terms of marine, exploration and scientific researches are relatively weak, which is not consistent with its power identity throughout the world. Therefore, China should begin to research on the broad ocean to prosper both the nation and state through it. Furthermore, China has to make tireless efforts to understand the ocean and take advantage of it with reasonable and legitimate use based on deepening researches, which cannot only consolidate our marine power but also further upgrade national power and at the same time provide powerful and scientific support for marine law enforcement, development and management.

\section{The Proposal of 'Maritime Silk Road'}

"Maritime Silk Road" emerged in 200 BC Qin-Han dynasties, which was an important marine road for ancient China to communicate with the worlds in terms of politics, economy, business, culture, science and religion. Time-honored "maritime silk road" has achieved universally acknowledged success. Therefore, in nowadays' development trend, the proposal of "maritime silk road" should be easily accepted. However, "21st-century maritime silk road" is different from the historical one, which is not simple duplication while the 21 st-century has already fully demonstrated the differences. It is rich in content, which does not only clear the region and time but also emphasize that China, as a responsible power in new era, should take up the mission and historical responsibilities. What's more, it connects the Asian-Pacific region so as to link up those with the most rapid, potential and active economic powers all over the world. However, Chinese people and people along the road have to make unremitting efforts to know how to live a peaceful as well as prosperous life, and share the bonus of Chinese economy and world economy growth.

In this context, China begins to strengthen the exploration and researches on marine. With the help of "21st-century maritime silk road" national strategy, China promotes additional exploration 
in terms of marine, the mutual development of multi-disciplinary fields so as to bring its function in international stage into full play. At the same time, scientifically intervene and manage the marine affairs is beneficial to raise our profile and status. Moreover, the participation in drafting and formulating marine international law can also empower China [1].

\section{Advantages of Russia in Terms of Exploit Marine}

It is well known that Russia is one of the maritime powers throughout the world, which is adjacent to 12 seas with a 43,000 KM coastline and 7 million square kilometers area. No matter military power or strategic thinking, naval or submarine, weapon or marine information, Russia can be called one of the worlds' marine power. In recent years, Russia keeps increasing the naval military budgets and actual spending continues to grow. Besides, Russia applies the latest scientific technology and advanced process technology to weapons and manufacturing, hoping to improve the quality and performance and thus revive its powerful marine power and continue the glory in 1980s to return back to the dominance in terms of sea.

In addition to military force, China has to pay attention to Russia's exploring the surrounding marine, researches and investigation. Early in 2004, Russia has complied the first map showing the bottom of the Arctic, which does not only show the storage of oil and gas field with prospect of drilling but also can provide necessary protection for the safe sailing of warship and merchant ship in Arctic sea. Moreover, Russia sets underground resource offices according to regions to carefully investigate the marine topography, tectonic structure as well as distribution of mineral deposits. Based on this, Russia will carefully compile data to clear the seabed resource distribution of Russian continental shelf, various oceans, Arctic and the South Pole in order to evaluate the potential of various mineral and oil in order to have the maximum to invest on industrial development and manufacturing to guarantee the national economic security [2].

The area of Russian congenital shelf is about 6,200,000 square kilometers, among which 4 million is hydrocarbon potential area with its workable reserve being 90-100 billion tons. In addition, the accumulated workable reserve of offshore gas and oil filed is about 10.8 billion tons, among which $52 \%$ can be used for industrial purpose $(\mathrm{A}+\mathrm{B}+\mathrm{C} 1)$ with about 8.5 billion tons. Technically, the recoverable natural gas is estimated about 47 trillion cubic meters and a half can be used for industrial purpose [3]. Oil \& gas exploration and development has always been a prominent task of Russia's geological survey, especially when the oil and gas resources continue to decrease in West Siberia Russia has to pay more attention on the exploration and exploitation of offshore gas and natural oil. Russia is rich in continental shelf gas and oil, yet keeps asking the United Nations for the sovereignty of Arctic ocean's continental shelf in order to guarantee the legal occupation and utilization of the energy in the future, which can also ensure that its military strength and political status can excel over other countries and have discourse power and initiative.

Along with the global warming, the surface of Arctic ocean no longer freezes, and the Arctic is gradually included as an important area of Russia while carrying out marine strategies. It is reported that, the Arctic occupies one fourth of the unknown oil and natural gas resources throughout the world. For this reason, most countries are carrying out scientific explorations in Arctic with the position of northern shipping path being highlighted while Russia and surrounding countries are competing for its property and rights of resource extraction.

Early in 2001, Russia has issued materials to the United Nations to request for the property of a 1,200,000 Arctic congenital shelf, covering from the coastline to 650 kilometers extending to the Arctic ocean, including north pole based on the article 76 of United Nations Convention on the Law of the Sea. This area may cover 4.9 billion tons oil and gas.

In July 2007, Russian scholar Artur Chilingarov entered into Arctic ocean with a team, they conducted a geological examination on Lomonosov Ridge and found that it connects with Russia's Siberian Continental Shelf. Then on 2nd August, this scientific expedition team stuck a Russian flag in 4261 meters seabed, which is made of titanium alloy and can be reserved for about 100 years [4].

Thus it can be seen that, Russia does not only have broad sea areas, rich congenital shelf mineral resources, scientific power but also can guarantee full exploration and exploitation. What's more, 
Russia is able to take advantage of the technology, scientific research and achievements, marine legal lacuna to take the initiative to make and perfect the law based on researching on the international laws and regulations in order to win the establishing right and voice to reap benefits and serve the national interest.

\section{New Cooperation Means between China and Russia in Terms of Marine}

To build the '21st-century Maritime Silk Route' is a national development strategy proposed by China in the new world structure, which has been implement gradually. At this time, we have to grasp the opportunity to develop extensively. On the one hand, we can strengthen the communication with countries and areas along the route so as to assess the situation and on the other hand, we can further promote the cooperation in terms of economy, politics and culture, taking the mutual development as a goal.

The advantages of marine exploration and exploitation of Russia cannot be ignored. What's more, wise men can correct their own by other's faults. Therefore, China can refer to advantages of Russia in terms of marine development to strengthen their cooperation and communication so as to gradually explore new cooperation means which should be consistent with the world development trend and thus come out a new way in marine exploitation with Chinese characteristics.

With the global warming, the coverage area of Arctic glacier is reducing and the sea ice is shrinking in summer. Gradually, the strategic position of Arctic ocean is highlighted and a sea shortcut linking Arctic ocean, Pacific and the Atlantic Ocean: 'Northern Sea Route' emerges (Северный морской путь, Russian saying is respected, this paper adopts English translation 'Northern Sea Route). If this route is unblocked, then China's ocean shipping distance (from Pacific ocean to Atlantic ocean') shall be double shortened which will not only bring along with huge economic interest but also innovate a new marine route to avoid the Somali pirates and control in Malacca with profound strategic meaning.

In the following 50 years, 'Northern Sea Route' will challenge the sea route of the Suez and Panama canals. It is known to all that, the sea route linking Asia to Europe is 13,000 miles. So, if the 'Northern Sea Route' is fully open, the distance from Asia to Europe shall be shortened by 5100 miles which will inevitably exert a tremendous impact on the business, international trade and world's economy[5].

Some scientists predict that the Arctic ocean in Summer will become real ocean without floating ice at the latest 2080 and the shipping will be unblocked. In addition, some scientists hold the idea that the sea ice in summer Arctic will be totally melt before 2050 [6].

Since Russia begins to open the "Northern Sea Route" shipping, relevant basic infrastructure guarantees are implemented based on plan. The transportation volume is doubled in 7 years when Russia begins to open this route. Experts predict that the cargo throughput of 'Northern Sea Route' shall be at least 30 million tons per year. According to Rossiyskaya Gazeta, the transport volume of Northern Sea Route will be 10 times comparing to now between 2020 and 2022 [7]. All of the above show that "Northern Sea Route" will exert profound economic value with huge commercial potential and the "Northern Sea Route"as well as the strategic position of the Arctic cannot be ignored.

However, the law of Russia asks that all ships have to obtain the admission if they want to ship across 'Northern Sea Route'. Besides, Russia forces to buy icebreaking and navigation service, which breed wide discontent in world community. Besides, even though Russia provides necessary information about meteorology, hydrology and sea ice, its basic infrastructure is old and the shipping system cannot meet the international operations and business requirement, meanwhile relevant international organizations design emergency systems which cannot be implemented because of shortage of international harmonization. Moreover, the natural condition in Arctic is bad and far away, once there is accident, various departments of various countries should collaborate to conduct the rescue, which is utter difficult. To conclude, there are different opinions in navigation law and recognition to carry out commercial transportation based on 'Northern Sea Route'. At the same time, there is a great deal of uncertainty in politics. All in all, the above problems are 
unfavorable factors which hinder China and the world at large to adopt it to carry out commercial shipping.

Therefore, China cannot simply take "Northern Sea Route" as an important shipping transportation channel but should include its development into maritime power strategy from the national level so as to reposition it and carry out a layout to make it an important issue while carrying out economic cooperation with Russia. "Northern Sea Route" will innovate a new ocean shipping pattern for us to choose, which cannot only avoid the monopoly control of Malacca as well as the Somali pirates but also increase the chance for us to explore the Arctic pole. So, apparently, China should deal with the development as well as exploitation of "Northern Sea Route" to participate in the discussion and development of Arctic affairs to show the status and lay a solid foundation to become a maritime power[8].

As the biggest country along the "Northern Sea Route", Russia has established perfect management system. However, in badly cold environment, Russia needs allies so as to arrange the resources around the world to deal with incredible hardship. Therefore, Russia has to inevitably collaborate with other countries to mutually explore the Arctic and exploit tremendous resources. Meanwhile, the economic development speed of China has attracted worldwide attention while China and Russia has carried out cooperation in terms of energy, economic trade, politics, and military but the cooperation in the development and exploitation of Arctic pole is scant. China should be positive in dealing with the "Northern Sea Route" issue even though China is underdog, China has to grasp the opportunity to layout as early as possible so as to struggle for relevant rights [9].

China has to fully utilize the satellite and other advanced technology to explore the condition of the air environment above the Arctic (for example misty weathers and weathers that affect the sailing of commercial vessel), aquatic environment, floating ice so as to manufacture the ships which can be able sail in the Arctic (such as anti floating ice ability) [10]. Besides, only when China is able to grasp relevant data of Arctic ocean can it take advantage of "Northern Sea Route" to carry out commercial sail and effectively cooperate with Russia and other Nordic nations (including South Korea, Canada, Norway, Iceland and America) in terms of Arctic affairs.

\section{Conclusion}

It is known to all that except from "Northern Sea Route", Arctic also has abundant mineral, energy resources and other necessary capital goods which are beneficial to the stable development of gross national product in the future. Therefore, China should take " 21 st-century Maritime Silk Road" as the opportunity to carry out cooperation with Russia in traditional fields, and meanwhile focus on the exploration on Arctic as well as development and exploitation of 'Northern Silk Route' in order to bring along with the synergetic development of China and shore areas. Furthermore, China should participate in the arctic affairs to promote the discourse power as well as impact on Arctic areas.

\section{References}

[1] SH.F. Zhou, SH.L. Qin. Research on the Maritime Exploitation Strategy (Zhejiang University Press, China 2009), p. 17-20.

[2] X.M. Xu. Maritime Rights and Development Strategy (Beijing: China Ocean Press, China 2008), p. 215-220.

[3] B. Dou. Maritime Development Prospect of Russia: Journal of Ocean University of China (Social Science edition), Vol. 20 (2008) No. 2, p. 25-29.

[4] Information on http://news.sohu.com/20150805/n418226781.shtml.

[5] ZH.F. Li. Analysis on Chinese Strategy based on Northern Sea Route: China Soft Science, Vol. 23 (2009) No. 1, p. 1-7. 
[6] Translated by X.B. Cui. Arctic will Run Out Ice Sooner than Expected: Liaison Office of CAA, Polar Research Institute of China: Foreign Polar Investigation Collection, Vol. 6 (2009) No. 14,

[7] J.SH. Wei, J.L. Shu. Analysis on the Northern Sea Route and Arctic Development Strategy: Journal of Northeast Asia Studies, Vol. 2 (2013) No. 6, p. 52-58.

[8] J.Y. Li, CH.Y. Zhang. The Strategic Concept for China and Russia Carrying out 21st-century Northeast Silk Road: Journal of Northeast Asia Studies, Vol. 4 (2015) No. 3, p. 75-83.

[9] ZH.M. Liu. World Maritime Politics and Chinese Maritime Development Strategy. (Current Affairs Rress, China 2009), p. 143-157.

[10] Y.ZH. Li, X.M. Xu. Ocean Century and Chinese Maritime Development Strategy. (Press of Ocean University of China, China 2006), p. 317-346.

\section{Introduction to the Author:}

Wei Xing (1985-), female, Xianyang Shaanxi, Hainan Tropical Ocean University, Department of Russian. Lecturer, director, doctor, research field: Russia's national condition

\section{Address:}

Qiongzhou college, No.1 Yucai Road, Sanya, Hainan Province. 572022, weixing118@163.com, 18089183208 